\title{
Carbon is forever: A climate change experiment on cooperation ${ }^{\text {is }}$
}

\author{
Giacomo Calzolari $^{\mathrm{a}, \mathrm{b}, \mathrm{e}}$, Marco Casari ${ }^{\mathrm{a}, \mathrm{c}, *}$, Riccardo Ghidoni ${ }^{\mathrm{d}}$ \\ a Department of Economics, University of Bologna, Piazza Scaravilli 2, 40126, Bologna, Italy \\ b CEPR, United Kingdom \\ c IZA, Germany \\ d Department of Economics, Tilburg University, 5000LE, Tilburg, the Netherlands \\ e Department of Economics, European University Institute, Italy
}

\section{A R T I C L E I N F O}

\section{Article history:}

Received 22 November 2016

Revised 11 September 2018

Accepted 14 September 2018

Available online 21 September 2018

\section{JEL codes:}

C70

C90

D03

Q54

\section{Keywords:}

Stock externalities

Public goods

Inequality

Dynamic games

\begin{abstract}
A B S T R A C T
Greenhouse gases generate impacts that can last longer than human civilization itself. Such persistence may affect the behavioral ability to cooperate. In a laboratory experiment, we study mitigation efforts with dynamic externalities in a framework that reflects key features of climate change. In treatments with persistence, pollution cumulates and generates damages over time, while in another treatment it has only immediate effects and then disappears. We show that with pollution persistence, cooperation is initially high but then systematically deteriorates with high stocks of pollution.
\end{abstract}

(C) 2018 The Authors. Published by Elsevier Inc. This is an open access article under the CC BY-NC-ND license (http://creativecommons.org/licenses/by-nc-nd/4.0/).

\section{Introduction}

Unless major efforts are undertaken to reduce greenhouse gas emissions (GHG), climate change will reach dangerous levels within this century. The impacts will be global, with uncertainties in their magnitude and geographical distributions, and with high degrees of irreversibility and persistence (IPCC, 2014). Coordinating international actions in regard to mitigation is notoriously difficult. A major reason is the temptation of opportunistic behavior by each single country that can benefit from the mitigation efforts of others without paying the costs of reducing the carbon intensity of their economy (Nordhaus, 2013).

\footnotetext{
We are thankful to Valentina Bosetti, Massimo Tavoni, Alessandro Tavoni, Peter Martinsson, and seminar participants at Fondazione Eni Enrico Mattei, University of Gothenburg, European University Institute, Fourth IAERE Annual Conference, Tilburg University, London School of Economics, EWEBE 2017, VU University Amsterdam, Collegio Carlo Alberto, International Workshop on the Economics of Climate Change and Sustainability at the University of Bologna, Goethe University Frankfurt, and 2018 ESA World Meeting. Furthermore, we would like to thank the editor and two anonymous referees for very helpful comments. Casari acknowledges financial support from the Italian Ministry of Education, Universities and Research through the FIRB-Futuro in Ricerca grant (Project No. RBFR084L83).

* Corresponding author. Department of Economics, University of Bologna, Piazza Scaravilli 2, 40126, Bologna, Italy.

E-mail addresses: giacomo.calzolari@unibo.it(G.Calzolari), marco.casari@unibo.it (M. Casari), r.ghidoni@uvt.nl (R. Ghidoni).
} 
Here we study the role of the long-run persistence of GHG emissions in the atmosphere, which makes climate change a dynamic social dilemma. In particular, carbon dioxide is the most important pollutant responsible for anthropogenic climate change, and a considerable portion of its current stock will last for well over a millennium, which - on the time scale of human civilization basically means forever (Inman, 2008).

The research question is whether and how such long-term persistence of pollution affects the ability of societies to cooperate. This aspect has been singled out in the literature as one of the factors that hamper cooperative efforts in mitigating climate change (Wagner and Weitzman, 2015). There may be multiple reasons for it that relate to the strategies adopted and the learning process. Decision-makers may be myopic, in the sense that they consider only the short-run consequences of their actions but not those in the long-run. ${ }^{1}$ Coordinating on a specific equilibrium may be harder in a dynamic as opposed to a static social dilemma. Furthermore, dynamic dilemmas involve irreversibility due to the lasting impact of pollution, and hence the consequences of past choices are harder or impossible to undo. These elements are tied to behavioral aspects, which we study by means of a laboratory experiment.

We model the climate change game as a strategic interaction among long-lived decision-makers in the absence of a legally binding treaty, where each decision-maker independently chooses its level of GHG emission at each point in time. Pollution benefits the decision-maker that emits it because it is linked to economic production, but it has negative externalities in the form of damage for all decision-makers. More precisely, we consider a public good game, and modify it in order to capture salient characteristics of the climate change dilemma.

We characterize this platform from a theoretical point of view and study its behavioral properties with an experiment by varying the degree of persistence of GHG emissions. In a Persistent treatment, the global emissions generated in one round remain fully in the atmosphere in the next rounds and indefinitely cumulate into a stock of pollution. Conversely, an Immediate treatment reproduces a static although repeated social dilemma, where the entire damage of the current emissions is suffered within the current round. Finally, a Halving treatment is an intermediate case, where emissions cumulate from one round to the next but the stock depreciates - halving in each round - because pollution dissipates. In all treatments the indefinite horizon gives rise to multiple equilibria, creating opportunities for partial or full cooperation. Our main theoretical benchmarks are the socially optimal level of emissions and the constant-actions Markov perfect equilibrium. We calibrated the parameters of the experiment in a way such that these benchmarks are identical across treatments. Hence, differences in behavior will easily reveal which scenario is most conducive to cooperation in mitigation efforts.

What emerges from the experiment are distinct patterns of behavior under static vs. dynamic externalities. More precisely, the persistence of pollution has effects on the trend and strategies that decision-makers adopt to sustain mitigation policies. Under dynamic externalities, initial emission levels are low and they are followed by an upward trend steeper than under static externalities. This pattern seems consistent with individual strategies conditioning emissions on the level of the stock of pollution. When the situation becomes critical in terms of cumulated stock, participants in the Persistent treatment are increasingly less able to support high levels of cooperation.

One must acknowledge the limitations to the external validity of most economic experiments on climate change. In the laboratory, decision-makers are individuals and not nations. The number of players involved is usually rather small. Laboratory communication hardly resembles the process of international climate negotiations. That said, the available field evidence exhibits major drawbacks, some of which can be circumvented through experiments. In the field, many key parameters are difficult to measure. Consider for instance the returns from cooperation, the discount factors, and the expectations about the damage caused by climate change. Laboratory experiments make it possible to set these parameters, render them observable to the experimenter and the participants, and establish causal relations among variables (Falk and Heckman, 2009).

We place the contribution of this paper in the context of the experimental literature on climate change and on cooperation with dynamic externalities (Section 2). We then present the theoretical platform of analysis (Section 3 ) and describe the experimental design (Section 4). Finally, we report the results (Section 5) and conclude with a discussion of the results (Section 6).

\section{Literature review}

This paper contributes to the experimental literature about dynamic social dilemmas and about cooperation in a climate change set-up. With few exceptions, existing public good experiments have a static set-up. Climate change externalities are instead dynamic because they depend on the stock of pollution accumulated in the atmosphere and not just on the yearly flow. Overall, cooperation in dynamic set-ups appears more difficult than in static ones. The seminal paper by Herr et al. (1997) investigates extraction in a finite horizon common-pool resource experiment contrasting a static externality with a dynamic one, and reporting lower payoffs with dynamic externalities. Battaglini et al. (2016) show that when contributions to a nondepletable public good are irreversible they are lower than under reversibility. Our experiment furnishes novel evidence by focusing on a climate change game with an indefinite horizon. Comparing a static externality to a dynamic externality with different degrees of persistence, we identify higher initial cooperation followed by its significant deterioration when persistence is in place. We adopt a climate change framework that builds on the model of Dutta and Radner (2004, 2009). The second of

\footnotetext{
${ }^{1}$ A noteworthy example, although not modeled here, is that politicians may be short-sighted because of re-election concerns and uncertain voters' preferences (Köke and Lange, 2017).
} 
these theoretical papers identifies "greenhouse traps", i.e. equilibria in which the current stock of pollution affects emissions decisions. Interestingly, in Section 5 we document behavior in our Halving treatment that can be interpreted as consistent with traps of this type.

With respect to the standard public good experiment, we have modified the action space, the gain-loss frame, the duration, and players' asymmetries. First, in our game, the theoretical benchmarks are interior points of the action space, in contrast with the typical public good experiment, where social optimum and Nash equilibrium are at the corners of the action space (Laury and Holt, 2008). Second, the choice concerns a public bad, as in the case of climate change: all endowments are in the common project by default, and everyone decides how much to withdraw from it to their private account (Andreoni, 1995; Khadjavi and Lange, 2015). ${ }^{2}$ Third, we implement a long-run interaction in the laboratory given that societies are long-lived entities and climate change has consequences in the distant future. The time horizon is indefinite, implemented through a continuation probability after every round. ${ }^{3}$ Fourth, we introduce an asymmetry in individual earnings in order to mirror the wide income gaps among countries, which is a major issue in addressing climate change because it may undermine cooperation (Tavoni et al., 2011). Using a public good terminology, in our set-up the return from the private account is lower for a poor than for a rich player type.

The most closely related experiments are Pevnitskaya and Ryvkin (2013), Sherstyuk et al. (2016), and Ghidoni et al. (2017). Their set-up is similar to ours but none of them studies the impact of pollution persistence. Pevnitskaya and Ryvkin (2013) study the role of framing and time horizon on cooperation. Under a finite horizon, participants were faster in learning to cooperate, but increased emissions in the last round. They have persistence rate of 0.75 and groups of 2 members. Sherstyuk et al. (2016) compare overlapping generations to long-lived agents, allowing for access to past history and intergenerational advices. With overlapping generations, cooperation became harder to sustain due to both limited incentives and greater strategic uncertainty. They have a persistence rate of 0.3 and groups of 3 members. Finally, Ghidoni et al. (2017) consider an indefinite horizon, like the other studies above, but, unlike them, only consider static externalities. The study decouples emission choices from realized damage through the introduction of randomness and delay so as better to identify individuals' cooperative strategies. Their groups comprise 4 members. We will further discuss these papers in Section 5.

The impact of income inequality studied in Ghidoni et al. (2017) and Tavoni et al. (2011) is instead absent from Pevnitskaya and Ryvkin (2013) and Sherstyuk et al. (2016). Tavoni et al. (2011) is one of the first papers to study inequality in climate change experiments. Strong inequality in earnings within a group hampered cooperation. Their study belongs to a branch of the literature pioneered by Milinski et al. (2008) that models climate change as a collective catastrophe that can happen if cooperation remains below a threshold. Participants can either keep their endowment in a private fund or invest it in mitigation. If, by the end of the experiment, the group's cumulated investment in mitigation is below a known threshold, the catastrophe of losing everything takes place with some probability. ${ }^{4}$

Within the Milinski et al. (2008) approach to modeling the dynamic climate game, two other experiments investigate aspects that the present paper neglects. Bosetti et al. (2017) study the interplay between mitigation and investments in a clean technology. In our paper, instead, the only available action concerns mitigation and no other tool is available. Finally, Hauser et al. (2014) investigate the role of voting mechanisms when managing a common pool with threshold under an indefinite horizon and with a catastrophic risk that would fall on the next generation. Here instead we only consider individual voluntary contributions.

\section{The model}

\subsection{The climate game}

We consider a group of $N \geq 2$ long-lived decision-makers interacting over an indefinite number of rounds in a game (sequence, henceforth). At any round $t \in\{0,1, \ldots\}$, there will be an additional round with probability $\delta \in[0,1)$, or else the sequence will end at $t$ with probability $(1-\delta)$. Decision-makers never know whether or not they are in the last round. The continuation probability $\delta$, as well as all other parameters of the game, are public information.

In every round $t$, each decision-maker $i=1,2, . ., N$ chooses its level of emission $e_{i}(t)$ from an interval ranging from 1 to a common finite upper-bound. Choices are simultaneous. Emissions are the sole input in the production of an output that is exclusively enjoyed by the emitting subject according to a production function specified below. After every round, decisionmakers observe the current individual emission $e_{i}(t)$ of everyone in the group.

Over the rounds, global emissions accumulate into a stock of pollution according to the following dynamic equation:

\footnotetext{
${ }^{2}$ Andreoni (1995) and Khadjavi and Lange (2015) find that, if participants can only withdraw from the common project, cooperation is lower than when they can contribute to it.

${ }^{3}$ Experiments with indefinite repetitions are common with the prisoner's dilemma (e.g. Camera and Casari, 2009), but are few and far between with public goods (Battaglini et al., 2016). Climate negotiations typically involve numerous players and a wide action space.

${ }^{4}$ Some experiments embed scientific uncertainty and ambiguity in climate tipping points. Empirically, the threat of a catastrophe enhances cooperation if the uncertainty on the tipping point is low. However, this deterrence effect disappears for high levels of uncertainty (Barrett and Dannenberg, 2012, 2014) or ambiguity about the tipping point (Dannenberg et al., 2015).
} 


$$
E(t)=\sigma E(t-1)+\sum_{i=1}^{N} e_{i}(t),
$$

where $\sigma \in[0,1]$ is the persistence rate of past emissions. Hence, if $\sigma=0$ all emissions dissipate at the end of every round, while if $\sigma=1$ emissions last forever. At the beginning of the sequence, the initial stock of pollution is $E(0)=E_{0} \geq 0$.

Each decision-maker privately benefits from the output produced through its own current emission, but, in absolute terms, all $N$ decision-makers are equally damaged by the stock of global emissions accumulated up to the current round. The instantaneous payoff of decision-maker $i$ is given by benefits from own output minus climate damages:

$$
u_{i}(t) \equiv \gamma \ln \left(a_{i} e_{i}(t)\right)-\frac{c}{N} E(t) .
$$

Emission intensity of production is linear and time-invariant: one unit of emission grants $a_{i}>0$ units of income. The natural logarithm implies a declining marginal utility of income. ${ }^{5}$ The parameter $\gamma>0$ serves only for rescaling.

We introduce heterogeneity by assuming two types of decision-makers in equal numbers: poor (type $p$ ) and rich (type $r$ ), which differ only in the level of one parameter, $a_{r}>a_{p}$. Note that, for the same emission level, type $p$ decision-makers contribute just as much to climate change as type $r$ ones. Hence, the aggregate volume of emissions is in potency the same for types $p$ and $r$, because the upper-bound in emission is the same. ${ }^{6}$

Finally, emissions damages increase linearly in the stock of pollution according to the parameter $c>0$. Unlike in a standard public good game, payoffs can be negative in the case of a lack of international cooperation, because Equation (2) is an additive function. ${ }^{7}$ Although in absolute terms the damage is equal for rich and poor decision-makers (parameter $c$ ), in relative terms it will harm poor decision-makers more than rich ones since the latter can always obtain higher benefits from their emission. This feature reproduces an aspect of the field: poor countries are predicted to suffer from climate change relatively more than rich countries. ${ }^{8}$ Describing the difference between rich and poor decision-makers only in terms of their income and relative damages is a simplification. However, in the experiment, this will allow us to precisely pin down the impacts of this source of inequality, abstracting from other sources (e.g., differences in available technologies or environmental footprints).

\subsection{Theoretical benchmarks}

Here we outline the social optimum and three different equilibrium strategies of the game described in the first part of this section. For each of these benchmarks we will emphasize key properties that we will then contrast with the experimental evidence. As we will see, the Markov perfect equilibrium (C-MPE) of the climate game is far from delivering the socially optimal level of emissions. Participants, however, could achieve the social optimum by coordinating on a constant trigger equilibrium (CTE). They could also support full or partial cooperation by following non-constant Markov strategies (NC-MPE) where emissions depend on the current level of the stock of pollution. Proofs are in Appendix A.

We will interpret the continuation probability $\delta$ as the discount factor of an (intertemporally) risk-neutral decision-maker (Camera and Casari, 2009). Hence, each decision-maker maximizes the present expected value of its current and future payoffs (Equation (2)),

$$
v_{i}=\sum_{t=0}^{\infty} \delta^{t} u_{i}(t) .
$$

Social optimum. If decision-makers jointly maximize the unweighted sum of individual present-valued payoffs:

$$
v=\frac{N}{2}\left(v_{r}+v_{p}\right)
$$

they set a socially optimal emission that is constant over the rounds, and which, for any type of decision-maker, is equal to

$$
e^{*}=\gamma \frac{1-\sigma \delta}{c}
$$

The socially optimal emission $e^{*}$ is time-invariant and independent of the stock of pollution $E$ because of the linearity of the damage in $E$. It is obtained by equating the marginal benefit from the individual emission $\gamma / e_{i}$ to the marginal present-valued

\footnotetext{
${ }^{5}$ In their climate cost-benefit analyses, Nordhaus (2013) and Stern et al. (2006) assume a utility function that takes the natural logarithm of GDP per capita.

${ }^{6}$ Tavoni et al. (2011) model countries heterogeneity through pre-determined contributions to a climate protection account that leave countries with a different inheritance in terms of endowment level when they begin to make choices. In the present study, instead, heterogeneity stems from different population weights $a_{i}$, which implies a structural country difference originating from the lower economic yields from the same level of emissions.

7 Some scholars have employed a multiplicative function for damages (Nordhaus, 2013), while others have used an additive one (Dutta and Radner, 2004). There is consensus that the stock of pollution linearly impacts on temperature. Most scholars argue for a convex damage function in temperature (Burke et al., 2015) but others have used a linear approximation (Dutta and Radner, 2004). Linearity makes it possible to keep the experiment simple, as further discussed below. The number of decision-makers at the denominator of the damage rescales payoffs so that the social optimum emission $e^{*}$ does not depend on $N$.

${ }^{8}$ The channels are somewhat different, however, since in the field damages will be higher for poor countries because they are located in warmer climates (IPCC, 2014).
} 
group's damage,

$$
N \times \frac{c}{N}\left[1+\delta \frac{\sigma}{(1-\delta \sigma)}\right]=\frac{c}{1-\delta \sigma},
$$

which is itself independent of the stock $E .^{9}$ The socially optimal emission $e^{*}$ is the same for all decision-makers because with our payoffs the marginal benefit does not depend on $a_{i}$, and is decreasing in emission persistence $\sigma$.

Constant-actions Markov perfect equilibrium (C-MPE). In general, at any round $t$, Markov strategies map the current state, i.e. the stock of pollution $E(t)$, into the set of emissions. Simple and interesting equilibrium candidates are the constant-actions strategies that depend neither on the stock $E$ nor on the history of past emissions.

Proposition 1. For any $\sigma$, there exists a constant-actions Markov perfect equilibrium (C-MPE) that contemplates a constant level of emission for both $r$ and $p$ decision-makers and that is $N$ times the socially optimal emission, i.e. $e^{F}=N \times e^{*}$.

In a C-MPE each decision-maker equates the marginal benefit $\gamma / e_{i}$ to the marginal individual damage $\frac{c}{N(1-\delta \sigma)}$, which does not depend on $E$ because of the linear damage. When emissions entirely dissipate at the end of each round $(\sigma=0)$, the game becomes a repeated one, and the C-MPE corresponds to the Nash equilibrium of the stage game. Although when $0<\sigma \leq 1$ the game is a dynamic one, both marginal benefits and marginal damages from emissions do not depend on the stock. This property - also discussed in footnote 7 - simplifies the environment for the decision-makers and makes it possible to sustain the simple C-MPE.

Note that for any emission level e constant over the rounds, the stock $E$ converges to the steady-state $\mathrm{Ne} /(1-\sigma)$ under partial persistence $(0<\sigma<1)$. When instead pollution persists forever $(\sigma=1)$, the stock associated with constant emissions follows a trajectory $E(t, e)$ that diverges.

Constant trigger equilibria (C-TE). In our settings there also exist equilibria based on the history of play that may support a wide range of (cooperative) outcomes. In particular, we are interested to identify under which conditions the social optimum can be supported as an equilibrium outcome when decision-makers punish deviations on larger emissions with a reversion to constant strategies, in particular the C-MPE, $e^{F}$. We label the associated equilibrium as "constant trigger" equilibrium.

Proposition 2. If $\delta$ is higher than a threshold $\bar{\delta}>0$, then a (subgame perfect) Constant Trigger Equilibrium (C-TE) exists with individual emissions equal to the social optimum $e^{*}$ for any decision-maker $i$.

With the punishment of permanent reversion to $e^{F}$, the threshold is

$$
\bar{\delta}=\frac{1}{N-1}\left[\ln (N) \frac{N}{N-1}-1\right]
$$

that, for the structure of the payoffs in our model, only depends on $N$. More precisely, when $\delta>\bar{\delta}$, any emissions levels in [ $\left.e^{*}, e^{F}\right]$ can be supported as equilibrium outcomes. For future reference, we note that with $N=4$ (as in our experiment), the threshold $\bar{\delta}$ is close to 0.28 . In addition, emissions in $\left[e^{*}, e^{F}\right]$ can be supported in (subgame perfect) equilibria with punishments that are milder than in the C-TE: after a deviation, decision-makers revert to emission $e^{F}$ for a finite number of rounds $T$. As usual, this possibility comes with the requirement of a higher threshold $\bar{\delta}$ for any lower $T$.

Equilibria with non-constant Markov strategies (NC-MPE). When the persistence rate $\sigma$ is not nil, decision-makers may follow stock-dependent strategies that specify different emissions $e_{i}(E)$ depending on the current level of the stock, i.e. nonconstant Markov strategies. This is particularly interesting in our environment. As Dutta and Radner (2009) have shown in a similar model, non-constant Markov equilibria may in fact determine a rich pattern of emissions and stock of pollution.

The dependence of strategies on the stock of pollution can take many different forms. As said, with payoffs as in (2), the marginal effect of date-t emission $e_{i}(t)$ on payoffs is independent of $E(t)$. This intuitively implies that there exist no equilibria based on "simple" non-constant Markov strategies such as a proportionality rule $e_{i}(E)=\beta_{i} \times E$. ${ }^{10}$ However, with $\sigma>0$ decisionmakers can use the stock level as a visible coordination device. They may "target" a trajectory of the stock (which could be constant when $\sigma<1$ ) and use it as a reference and monitoring device to support cooperation.

Define $E(t, e)$ as the "long-run" stock of pollution when decision-makers constantly emit $e$ in any period, from $t$ onward. In particular, with $\sigma<1$, it is $E(t, e)=N e /(1-\sigma)$, and with $\sigma=1, E(t, e)=E(t-1, e)+N \times e$.

Proposition 3. Sufficiently many and patient decision-makers (respectively $N \geq \frac{e^{F}}{e^{F}-e^{*}}$ and $\delta \geq \bar{\delta}$ ) may coordinate on the following non-constant Markov perfect equilibrium (NC-MPE):

- if $E(t) \leq E\left(t, e^{*}\right)$, emissions lead to a stock $E\left(t^{\prime}, e^{*}\right)$ at some $t^{\prime}>t$ and remain constant at $e^{*}$ thereafter;

- if instead $E(t)>E\left(t, e^{*}\right)$, decision-makers emit $e^{F}$ and the stock converges to $E\left(t, e^{F}\right)$.

Proposition 3 considers the possibility to implement the socially optimal emission $e^{*}$. Analogous propositions could be

\footnotetext{
${ }^{9}$ The constant social optimum is also the consequence of an implicit assumption of no technological change. We rule out technological change to keep the experiment simple, although it could help to achieve climate policy objectives (Bosetti et al., 2012; Gerlagh and van der Heijden, 2015).

${ }^{10}$ The proof of non-existence of equilibria with "simple" Markov strategies is available upon request.
} 
obtained when implementing higher and less efficient levels of emission in the interval $\left[e^{*}, e^{F}\right]$, which would then be associated with different thresholds of $N$ and $\delta$. The idea of supporting this NC-MPE is the following. Consider first the case with $\sigma<1$ and constant long-run stock. Decision-makers set the target stock of pollution equal to the long-run socially optimal level, i.e. $E\left(t, e^{*}\right)=N e^{*} /(1-\sigma)$. If the stock is below $E\left(t, e^{*}\right)$, decision-makers guarantee that it reaches it - either smoothly or with a single "jump" in emissions - and remains forever at this "target" level with individual emissions $e^{*}$. Emissions higher than $e^{*}$ are dominated when $\delta \geq \bar{\delta}$, exactly the same threshold identified above for Proposition 2. If instead the stock "has gone too far", i.e. $E(t) \geq N e^{*} /(1-\sigma)$, the decision-makers act non-cooperatively forever onward with an individual emission equal to $e^{F}$. In this case the stock converges to the associated non-cooperative steady-state level $E\left(t, e^{F}\right)=N e^{F} /(1-\sigma)$. A single decision-maker may want to try and push $E$ back into the "good region" (i.e. below $E\left(t, e^{*}\right)$ ). However, if there are sufficiently many other decisionmakers emitting $e^{F}$, then even the strongest attempt (i.e. the decision-maker setting $e=0$ ) in the ideal situation (i.e. a stock of pollution just above $E^{*}$ ) would be a vain sacrifice. With the other $N-1$ decision-makers emitting $e^{F}$, the stock of pollution would remain above the target $E^{*}$ in any case, if $(N-1) e^{F} \geq N e^{*}$. This condition is equivalent to the one in the Proposition and is satisfied in our experimental set-up with $N=4, \delta=0.92, e^{F}=12$, and $e^{*}=3$. Dutta and Radner (2009) referred to this pattern of emissions as a "greenhouse trap". Interestingly, the stock of pollution could converge to $E\left(t, e^{F}\right)$ cyclically if, for some reasons, emissions undershoot and/or overshoot that target. ${ }^{11}$

When emissions persist forever $(\sigma=1)$, the socially optimal emission $e^{*}$ may be still implementable, even though the target must now be a trajectory $E\left(t, e^{*}\right)$ of the stock. As long as the associated trajectory of the stock "does not go too far", i.e. $E(t) \leq E(t$, $\left.e^{*}\right)$, decision-makers have no individual incentive to deviate from the socially optimal emission $e^{*}$. If instead, at any $t$, the stock overshoot $E\left(t, e^{*}\right)$, then cooperation breaks down and emissions revert to the C-MPE forever as in a "greenhouse trap".

These NC-MPE exhibit some interesting properties. Whatever the level of persistence $\sigma>0$, the emissions of a decisionmaker may remain constant with no immediate reactions to others' changes in emissions. This happens as long as global emissions keep the stock below the target level. Here the stock of pollution plays the role of allowing decision-makers to coordinate their actions with a target stock level and with no need to check all individual emissions systematically. This desirable property of NC-MPE must be contrasted with at least two difficulties in coordinating on a level of stock. First, the target level could be a trajectory that changes at any round. Second, a stock is not completely under a decision-maker's control: even if a decisionmaker is willing to reduce its own emissions, cooperation may still break down because the stock has already "gone too far". We will explore these possibilities in Section 5.

\section{Experimental design}

\subsection{Treatments}

We designed an experiment based on our climate game that comprises three treatments (Table 1): Persistent and Halving where the externality is dynamic -, and Immediate - where the externality is static. The three treatments cover the full range of possible persistence levels. In the Persistent treatment emissions never dissipate $(\sigma=1)$. This scenario roughly approximates the climate change problem where the most significant GHG persist in the atmosphere for a very long time. Out of one ton of carbon dioxide emitted today about $50 \%$ will remain after 30 years and from $20 \%$ to $40 \%$ will remain after 1000 years (IPCC, 2007). The corresponding value of $\sigma$ that will generate this degree of persistence is 0.98 for the 30-year horizon and 0.998-0.999 for the 1000-year horizon. Other GHG, instead, are short-lived. Methane, for instance, can be removed from the atmosphere by a much faster chemical reaction and persists for decades. In the Halving treatment half of the stock of pollution dissipates after every round $(\sigma=0.5)$. Finally, in the Immediate treatment there is no stock accumulation and all the damage happens in the current round $(\sigma=0)$. Some pollution externalities are best approximated by the Immediate treatment, such as noise pollution, and others by the Persistent treatment, such as radioactivity from nuclear waste elements like Plutonium 244 (with a half-life of 80 million years). See Fig. B.1 of the Appendix for a graphical illustration of the damage profiles across treatments.

Climate change is a long-term problem, and the experimental set-up incorporates this aspect through indefinite repetitions. After every round there is a continuation probability of interaction of $\delta=0.92$. Many simulations of climate change consider scenarios for the year 2100, which is 85 years distant from today. In the experiment, each sequence has an expected length of $1 /(1-\delta)=12.5$ rounds, which can be interpreted as a decision every 7 years up to $2100 .^{12}$ Consider also that for risk-neutral agents this set-up is theoretically equivalent to an infinite time horizon with a discount factor of 0.92 (Dal Bó and Fréchette, 2018). While individuals have a finite life, societies can be treated as long-lived. This calibration of $\delta$ creates conditions favorable for the emergence of cooperation because the shadow of the future is sufficiently large to sustain the socially optimal emission. From a theoretical point of view, what is required is that $\delta$ be larger than 0.28 (Proposition 2).

In our design the damage from the marginal emission is identical across treatments in terms of its present value. For each unit of emission, the expected damage is 33.375 tokens in all treatments but varies in how it is spread over time. In the Immediate

\footnotetext{
${ }^{11}$ Emissions and stock respectively larger than $e^{F}$ and $E\left(t, e^{F}\right)$ may temporarily occur off equilibrium in the punishment phase of non-Markov equilibria. We discuss the possibility of these more sophisticated strategies and equilibria at the end of Section 5.

12 The initial round starts with no past history of emissions, and we set the initial stock of pollution $E_{0}$ equal to 0 . Varying the initial stock of pollution can be an interesting treatment dimension (e.g. Tavoni et al., 2011) that we leave for future research.
} 
Table 1

Overview of the experiment.

\begin{tabular}{|c|c|c|c|c|}
\hline & & \multicolumn{3}{|c|}{ Treatments } \\
\hline & & Immediate & Halving & Persistent \\
\hline \multicolumn{5}{|c|}{ Parameters } \\
\hline$\delta$ & Discount factor (continuation probability) & 0.92 & 0.92 & 0.92 \\
\hline$\sigma$ & Pollution persistence & 0 & 0.5 & 1 \\
\hline$c$ & Damage in the current round & 33.375 & 18.0225 & 2.67 \\
\hline$a_{r}$ & Population weight for rich decision-maker & 40.05 & 40.05 & 40.05 \\
\hline$a_{p}$ & Population weight for poor decision-maker & 8.01 & 8.01 & 8.01 \\
\hline$\gamma$ & Utility rescaling & 100 & 100 & 100 \\
\hline$E_{0}$ & Initial stock of pollution & 0 & 0 & 0 \\
\hline$N$ & Number of players in a group & 4 & 4 & 4 \\
\hline \multicolumn{5}{|c|}{ Benchmarks } \\
\hline$e^{*}$ & Social optimum (individual emission) & 3 & 3 & 3 \\
\hline$e^{F}$ & Constant Markov perfect equilibrium & 12 & 12 & 12 \\
\hline \multicolumn{5}{|c|}{ Observations } \\
\hline Nur & f participants (main task + side task) & $60+15$ & $60+15$ & $60+15$ \\
\hline Nur & froups & 55 & 60 & 60 \\
\hline Nur & f sequences & 11 & 12 & 12 \\
\hline Ave & ength of a sequence & 10.8 & 8.3 & 8.8 \\
\hline
\end{tabular}

Note: All sessions but one were performed in May 2015: Immediate (20, 21, 27), Halving (28, 29, June 18), Persistent $(14,25,28)$. Session 20/05/2015 (Immediate) was interrupted during the third sequence for time constraints following the protocol described in footnote 20 . The unit for the average length of a sequence is a round in a sequence. According to Wilcoxon-Mann-Whitney (WMW) tests differences in the length of the sequences are not statistically significant when comparing Immediate vs. Persistent $(p$-value $=0.802)$ and Immediate vs. Halving ( $p$-value $=0.366$ ). When comparing Halving vs. Persistent, the WMW test detects a marginally significant difference $(p$-value $=0.089)$.

treatment the damage occurs entirely in the round in which the emission is done $(c=33.375)$. In the Halving treatment, half of the damage occurs in the current round $(c=18.0225)$ and the other half in the future. In the Persistent treatment, there is a damage of $c=2.67$ in the current round and of 2.67 in each future round. The expected value of the damage in the Persistent treatment is 33.375 , given an expected duration of 12.5 rounds.

Given this calibration of $\sigma$ and $c$, the socially optimal level of emission and the C-MPE are the same in all treatments (Proposition 1), allowing for easy comparison of the experimental results. Both theoretical benchmarks are internal elements of the action space: participants could emit any integer amount between 1 and 18 , where the social optimum is $e^{*}=3$ and C-MPE is $e^{F}=12$. Thus, participants were allowed to implement excessive restraint or overshoot in emissions. ${ }^{13}$

A group comprises $N=4$ decision-makers. This is a simplification in comparison to the over 190 countries who meet for climate negotiations. Consider, however, that in 2010 eight regions accounted for almost 2/3 of annual GHG emissions worldwide (EDGAR, JRC and PBL, 2016). Four regions accounted for more than half (China, USA, European Union 28, and Brazil). Limiting group size to four makes it possible to increase the number of independent observations while retaining the possibility of overcoming coordination issues and some degree of heterogeneity. Settings with four players are typical in many public goods games. ${ }^{14}$

There are two rich and two poor members in each group, randomly assigned, with an equal potential for emissions. The RICE model, for instance, has five poor regions and seven rich regions. Our design incorporates income inequalities of a comparable magnitude of those in the field. On average, the per-capita income in rich regions is 4.8 times higher than in poor regions $\left(\$ 34,085\right.$ vs. \$7125.9). ${ }^{15}$ In our design, for any level of emissions, the per-capita output of a rich participant is five times larger than that of a poor one. This is achieved by setting appropriate weights $a_{r}$ and $a_{p}$ (Table 1 ). By design there is no intrinsic conflict between concerns for efficiency and equality, since both motivations will induce participants to increase cooperation levels toward the social optimum level (in the Persistent treatment, this is true only in the long run). ${ }^{16}$

\footnotetext{
${ }^{13}$ The action space is similar to most public good experiments in terms of number of elements. The condition ensuring that $e^{F}$ and $e^{*}$ are the same for any $\sigma$ is determined as follows. Indicate with $\sigma_{h}$ the persistence rate in the Persistent treatment, and let $\sigma_{l}$ be 0 when $l=I m m e d i a t e$ or 0.5 when $l=H a l v i n g$. Then the damage coefficient in treatment $l, c_{l}$, is set to $c_{h} \frac{1-\delta \sigma_{h}}{1-\delta \sigma_{l}}$, where $c_{h}$ is the damage coefficient in Persistent.

${ }^{14}$ Meta-studies on public goods experiments detect a small impact of group size on cooperation (e.g. Fiala and Suetens, 2017).

15 We consider the 2010 average per-capita GNIs according to World Bank data for the regions of the RICE model. We label "rich" a region with a per capita GNI greater than \$12,745 in 2010 (World Bank's threshold for high income countries). Otherwise, the region is labeled “poor". Poor regions in RICE turn out to be Africa, China, Eurasia, India, and Other Asia $(N=5)$. Rich regions are EU, Japan, Latin America, Middle East, Russia, USA, and Other High Income ( $N=7$ ).

${ }^{16}$ In fact, poor decision-makers suffer more for the damages of higher emissions than rich ones only in relative terms, i.e. with respect to the individual benefits.
} 


\subsection{Procedures}

In our experiment, the instructions were expressed in a neutral language and did not use any term that could recall climate change (Appendix D). ${ }^{17}$ Overall 225 volunteers participated in the experiment. There were 25 participants in each session: 20 engaged in the main task described in Section 4.1, while 5 performed a side task with no other purpose than to keep them busy during the session. Participants assigned to the side task were those that displayed the lowest level of understanding of the instructions. These 5 participants had to guess the level of damage in the current round and in ten rounds from the current one for a given group of active participants. ${ }^{18}$ The alternative would have been to send them away, but this might have upset them. Moreover, we opted to exclude them instead of simply controlling for their quiz performance in the statistical analyses, because we thought that it was a cleaner way to obtain high quality data, since it prevented low score participants' actions from influencing others' behavior.

The 20 participants in the main task performed up to four repetitions (or sequences) of our climate change game. This allowed participants to gain familiarity with the complexities of the climate game. ${ }^{19} \mathrm{~A}$ sequence comprised an indefinite number of rounds, depending on random draws by the computer that were ex-ante unknown to participants and experimenter alike. ${ }^{20}$ Within each sequence, participants interacted with the same group (partner protocol). After every sequence, new groups were formed so that in following sequences no participant ever interacted again with a person that she had already met (perfect stranger protocol).

Climate change negotiations are performed by professionals, but we recruited college students. We aimed at ensuring that participants were well-qualified in the sense of having a good understanding of the rules. To this end: (i) instructions explained the task in a simple way and with extensive use of figures; (ii) the software was a user-friendly interface with a built-in simulator tool with which participants could compute present and future consequences of hypothetical emissions; (iii) all participants completed a comprehension quiz on the instructions (Appendix E); (iv) those with a poor understanding of the instructions were excluded from the main task; (v) after the quiz, everyone underwent a fifteen-round practice sequence playing against robots in order to familiarize themselves with the main task; (vi) after every round, we asked participants to write down on a record sheet their own and other group members' emissions in order to make sure that they had actively followed the play; (vii) participants experienced four separate sequences that were new restarts with identical rules; hence, they could learn by doing; (viii) the instructions explicitly stated that if everyone emitted 3, group earnings would be maximized (social optimum). More details on procedures (i)-(viii) are in Appendix B.

Table 1 reports some statistics on the experimental sessions. In every session five groups simultaneously played during a sequence. Overall, we managed to implement 11 sequences for the Immediate treatment, yielding 55 different groups $(5 \times 4+5 \times 4+5 \times 3)$. For the Halving and Persistent treatments, instead, we implemented 12 sequences yielding 60 groups for each one of these treatments $(5 \times 4+5 \times 4+5 \times 4)$. Participants in the main task were paid according to the total amount of tokens that they had earned in all the sequences: they received $€ 0.01$ for every 6 tokens plus a show-up fee of $€ 4$ in the Persistent treatment, $€ 5$ in the Halving treatment, and $€ 6$ in the Immediate treatment. Since cumulate earnings could be negative at the end of the experiment because of the damage, we ensured participants a minimum payment of $€ 10$. Average earnings for those who participated in the main task were $€ 17.6$; overall, 40 participants (20\%) earned $€ 10$.

Recruitment was done via ORSEE (Greiner, 2015) and participants were involved in at most one session. Instructions were read aloud and participants had a hard copy on their desks. Sessions took place at the BLESS laboratory of the University of Bologna using zTree (Fischbacher, 2007).

\section{Results}

After providing an overview of aggregate emissions across treatments, we present seven main results, where we compare emission levels of rich and poor participants (Result 1), show the effect of persistence on initial emissions (Result 2) and on emission trends (Result 3), as well as reporting disaggregated analyses on the strategies adopted by participants (Results 4-7).

The aggregate levels of emissions are 9.4 for the Immediate, 8.8 for the Halving, and 8.5 for the Persistent treatment when considering all rounds. They are computed as the means of the individual emissions within a group in a sequence. These emission levels are statistically indistinguishable across treatments, as one can see from a Tobit regression on groups' aggregate emissions

\footnotetext{
${ }^{17}$ For instance, we referred to emission choices as "production", and explained that one participant's production had two effects: to increase personal "revenue" and to "damage" earnings for everyone.

${ }^{18}$ They received $€ 0.25$ for each round of all sequences plus a show-up fee of $€ 5$. On average, low score participants overestimated damages in the current round of 50 tokens in the Immediate treatment, 17 tokens in the Halving treatment, and 12 tokens in the Persistent treatment. The lower precision of guesses in the Immediate treatment may be due to the higher sensibility of damages to the marginal emission (Table 1, parameter $c$ ). Due the random duration of the sequences, we can only evaluate the precision of guesses on the damage in ten rounds in a handful of cases. These guesses are quite noisy and inaccurate. The lack of proper incentives to predict damages may explain imprecisions.

${ }^{19}$ Participants in experiments with an indefinite horizon may need some repetitions of the supergame before converging to a stable outcome (Dal Bó and Fréchette, 2018). While the number of sequences per session may appear low, previous experiments have documented that sharp changes in behavior often take place already in early sequences.

${ }^{20}$ Participants were recruited for a maximum of $3 \mathrm{~h}$ and a half. If a session was still running after $2 \mathrm{~h}$ and 40 min, the experimenter announced that the current sequence was the last one and that the session would finish within the next $30 \mathrm{~min}$. The experimenter told participants that the exact minute at which the sequence was stopped was determined by a 30 faces dice roll, which was immediately rolled and observed by the experimenter but not by the participants.
} 
Table 2

Emissions under static vs. dynamic externalities.

\begin{tabular}{|c|c|c|c|}
\hline & $\begin{array}{l}\text { (1) } \\
\text { Individual emission } \\
\text { in round } 1 \text { of sequence } 1\end{array}$ & $\begin{array}{l}\text { (2) } \\
\text { Average group emission } \\
\text { in round } 1 \text { of all sequences }\end{array}$ & $\begin{array}{l}\text { (3) } \\
\text { Average group emission } \\
\text { in all rounds of all sequences }\end{array}$ \\
\hline \multicolumn{4}{|l|}{ Treatment dummies } \\
\hline Halving & $\begin{array}{c}-0.816 \\
(0.659)\end{array}$ & $\begin{array}{c}-0.792 \\
(1.048)\end{array}$ & $\begin{array}{c}-0.169 \\
(0.851)\end{array}$ \\
\hline Persistent & $\begin{array}{l}-1.358^{*} \\
(0.740)\end{array}$ & $\begin{array}{l}-1.921^{* *} \\
(0.955)\end{array}$ & $\begin{array}{c}-0.625 \\
(1.018)\end{array}$ \\
\hline Rich type & $\begin{array}{l}-0.929 \\
(0.709)\end{array}$ & & \\
\hline Sequence number & & $\begin{array}{l}0.592^{* * *} \\
(0.177)\end{array}$ & $\begin{array}{l}0.292^{*} \\
(0.175)\end{array}$ \\
\hline Length of past sequence & & $\begin{array}{l}-0.018 \\
(0.027)\end{array}$ & $\begin{array}{l}-0.035 \\
(0.055)\end{array}$ \\
\hline Length of current sequence & & & $\begin{array}{l}0.128^{* *} \\
(0.051)\end{array}$ \\
\hline Constant & $\begin{array}{l}7.538^{* * *} \\
(0.312)\end{array}$ & $\begin{array}{l}7.033^{* * *} \\
(0.973)\end{array}$ & $\begin{array}{l}7.594^{* * *} \\
(1.368)\end{array}$ \\
\hline Wald test $p$-value: Halving vs. Persistent & 0.414 & 0.247 & 0.607 \\
\hline Observations & 180 & 175 & 175 \\
\hline
\end{tabular}

Note: Tobit regressions with observations censored at 1 and 18. The unit of observation is a participant's emission in the first round (col. 1 ), the average group emission in the first round of a sequence (col. 2), and the average group emission in all rounds of a sequence (col. 3 ). Standard errors are clustered at the session level. The variable "Halving" ("Persistent") is a dummy taking value 1 in the Halving (Persistent) treatment, 0 otherwise. The variable "Length of past sequence" counts the number of rounds in the previous sequence; in sequence 1 it is set to 12.5 . * $p<0.1$, ${ }^{* *} p<0.05,{ }^{* * *} p<0.01$

(Table 2, col. 3). Non-parametric tests on groups' aggregate emissions in sequence 1 confirm the lack of significant treatment differences (Table C.1 in Appendix). One can express aggregate emissions in terms of cooperation rates, $1-\left[\left(e_{i}-e^{*}\right) /\left(e^{F}-e^{*}\right)\right]$ for $e_{i}$ in-between $e^{*}$ and $e^{F}$, to facilitate comparisons with other studies. Cooperation rates are $29 \%$ in Immediate, $35 \%$ in Halving, and $33 \%$ in Persistent. ${ }^{21}$

The analysis of aggregate emissions may be too coarse to properly identity the treatment effects of dynamic externalities. For this reason, we further explore our data, first by contrasting emissions of rich and poor participants and then by studying initial emissions and trends.

Result 1 (Rich vs. poor types). Average emissions of rich participants are usually lower than those of poor participants, but the difference is quantitatively small.

Support for Result 1 is provided in Fig. 1 and Table 3. Recall that theory predicts equal emissions for rich and poor participants (Proposition 1). In the experiment, rich participants emitted on average $6 \%-15 \%$ less than poor participants depending on treatments (Fig. 1). Table 3 reports Tobit regressions of individual emission choices controlling for a variety of relevant factors. The coefficient for a dummy that takes value 1 for rich participants is generally not statistically significant. ${ }^{22}$

We can place this finding in the context of two related studies. In a similar set-up, Ghidoni et al. (2017) find small differences in the same direction but generally not statistically significant. In a threshold public good game, Tavoni et al. (2011) report larger differences in the same direction and also a statistically significant link between the within-group earnings inequality and the ability to cooperate of a group: among those groups where rich participants contributed relatively more to the public good than poor participants did, groups that successfully cooperated are overrepresented. In our experiment this association is not statistically significant. When using as dependent variable the average emission of the rich-types divided by the overall group emission, a regression shows a statistically insignificant coefficient for a variable denoting those groups that successfully cooperated $(p$-value $=0.997, N=175) .^{23}$

In terms of cumulated earnings, rich participants ended up considerably better off than poor participants. On average, the relative earnings of a poor participant with respect to a rich one range from $38 \%$ to $66 \%$ depending on the treatment. In the C-MPE equilibrium, the predicted earnings gap ranges from $41 \%$ to $78 \%$ depending on the treatment.

We now zoom in on our data in order to highlight important treatment effects on the emission dynamics that remain undetected when considering aggregate emissions.

\footnotetext{
${ }^{21}$ These cooperation levels are in line with those found in the dynamic public bad experiments of Sherstyuk et al. (2016) and Pevnitskaya and Ryvkin (2013) in comparable treatments (49\% and 10-20\%, respectively). Long-run participants in Sherstyuk et al. (2016) achieved average individual emissions of 4.5 in a possible range of 1-11, with a social optimal at 3 and a C-MPE at 6. In Pevnitskaya and Ryvkin (2013) average individual emissions with indefinite horizon were between 8 and 9 in a possible range between 0 (social optimal) and 10 (C-MPE).

22 See Tables C.2 and C.3 in Appendix for robustness analyses using non-parametric tests on sequence 1 and additional regressions.

${ }^{23}$ OLS regression with clustered standard errors at session-level and controls for treatment dummies, sequence number, and length of current and past sequence. We define a group as successfully cooperating if its aggregate emission was lower or equal to seven. A robustness check where cooperative groups are those with an aggregate emission below the median one in that treatment confirms this result $(p$-value $=0.721)$.
} 


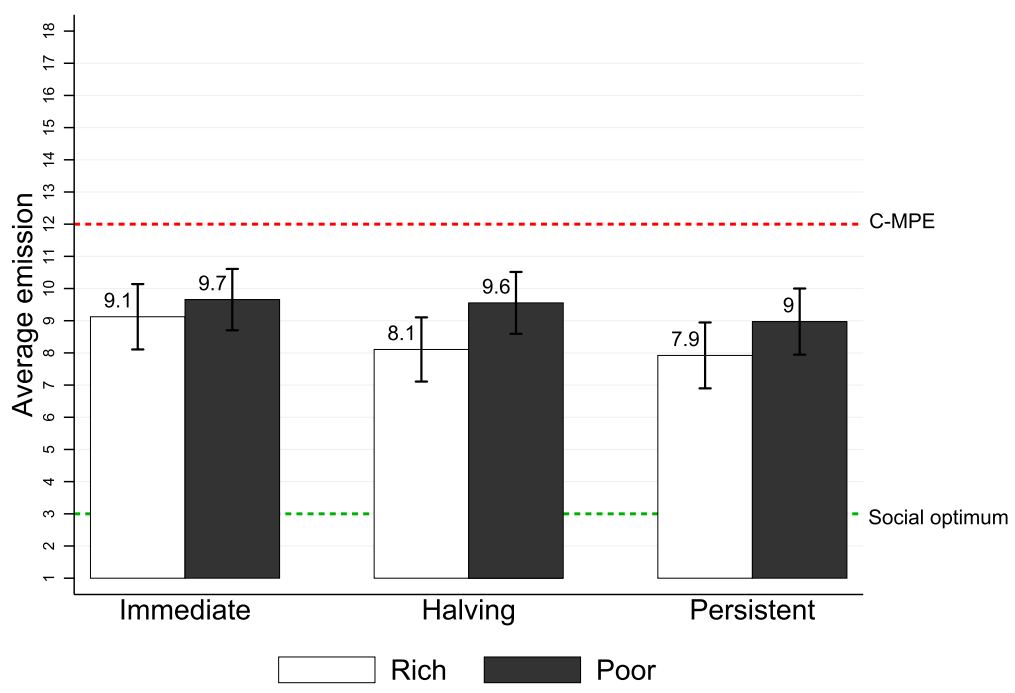

Note: The unit of observation is one type of participants of a group in the sequence. All sequences are included ( $N=55$ in Immediate, $N=60$ in Halving, $N=60$ in Persistent). We consider the average emission of the two rich (poor) participants of a group over all rounds of the sequence. The vertical segments represent the $95 \%$ confidence interval.

Fig. 1. Average emissions of rich and poor by treatment.

Table 3

Tobit regressions of individual emission.

\begin{tabular}{|c|c|c|c|c|c|}
\hline \multirow[b]{2}{*}{ Dependent variable: Individual emission in a round } & \multirow{2}{*}{$\begin{array}{l}\text { Immediate } \\
\text { (1) }\end{array}$} & \multicolumn{2}{|c|}{ Halving } & \multicolumn{2}{|c|}{ Persistent } \\
\hline & & $(2)$ & (3) & (4) & $(5)$ \\
\hline Rich type & $\begin{array}{l}1.164 \\
(0.860)\end{array}$ & $\begin{array}{l}-0.223 \\
(0.488)\end{array}$ & $\begin{array}{l}-0.989^{* * *} \\
(0.338)\end{array}$ & $\begin{array}{c}-0.676 \\
(1.582)\end{array}$ & $\begin{array}{l}-0.892 \\
(1.507)\end{array}$ \\
\hline Round number within a sequence & $\begin{array}{l}0.014 \\
(0.037)\end{array}$ & $\begin{array}{l}0.245^{\text {**** }} \\
(0.087)\end{array}$ & $\begin{array}{l}-0.062^{*} \\
(0.035)\end{array}$ & $\begin{array}{l}0.673^{* * *} \\
(0.067)\end{array}$ & $\begin{array}{l}-0.352 \\
(0.272)\end{array}$ \\
\hline Stock of pollution at the beginning of a round & & & $\begin{array}{l}0.106^{* * *} \\
(0.012)\end{array}$ & & $\begin{array}{l}0.024^{* * *} \\
(0.005)\end{array}$ \\
\hline Sequence number & $\begin{array}{l}0.209 \\
(0.336)\end{array}$ & $\begin{array}{l}1.192^{* * *} \\
(0.375)\end{array}$ & $\begin{array}{l}0.986^{* *} \\
(0.417)\end{array}$ & $\begin{array}{l}0.501^{*} \\
(0.266)\end{array}$ & $\begin{array}{l}0.312^{* * *} \\
(0.102)\end{array}$ \\
\hline Length of past sequence & $\begin{array}{c}-0.014 \\
(0.102)\end{array}$ & $\begin{array}{l}-0.148^{* * *} \\
(0.040)\end{array}$ & $\begin{array}{l}-0.005 \\
(0.043)\end{array}$ & $\begin{array}{l}-0.004 \\
(0.082)\end{array}$ & $\begin{array}{l}-0.002 \\
(0.029)\end{array}$ \\
\hline Mistakes in the quiz & $\begin{array}{l}0.220^{* *} \\
(0.090)\end{array}$ & $\begin{array}{l}0.609 * * * \\
(0.170)\end{array}$ & $\begin{array}{l}0.486^{* * *} \\
(0.062)\end{array}$ & $\begin{array}{l}0.450 \\
(0.346)\end{array}$ & $\begin{array}{l}0.202 \\
(0.200)\end{array}$ \\
\hline Limited liability & $\begin{array}{l}4.053^{* * *} \\
(0.189)\end{array}$ & $\begin{array}{l}0.881^{* *} \\
(0.428)\end{array}$ & $\begin{array}{l}-1.397^{* * *} \\
(0.405)\end{array}$ & & \\
\hline Constant & $\begin{array}{l}9.360^{* * *} \\
(1.620)\end{array}$ & $\begin{array}{l}6.278^{* * *} \\
(0.604)\end{array}$ & $\begin{array}{l}2.280^{* * *} \\
(0.703)\end{array}$ & $\begin{array}{l}4.264^{* *} \\
(2.107)\end{array}$ & $\begin{array}{l}7.051^{* * *} \\
(1.564)\end{array}$ \\
\hline Observations & 2380 & 2000 & 2000 & 2120 & 2120 \\
\hline Pseudo $R^{2}$ & 0.008 & 0.041 & 0.084 & 0.048 & 0.069 \\
\hline
\end{tabular}

Note: Tobit regressions with observations censored at 1 and 18 . The unit of observation is a participant in a round. All sequences are included. Standard errors are clustered at the session level. "Rich type" is a dummy taking value 1 if a participant is of type $r$, and 0 otherwise. "Length of past sequence" counts the number of rounds in the previous sequence; in sequence 1 it is set to 12.5 . "Mistakes in the quiz" counts the number of mistakes made by a participant in the quiz on the instructions. "Limited liability" is a dummy taking value 1 if the emission decision was made under limited liability (see footnote 24), and 0 otherwise. $* p<0.1, * * p<0.05, * * * p<0.01$.

Result 2 (Cooperation in round 1). Persistence lowers emissions in the initial decision of a sequence.

Support for Result 2 is provided by Fig. 2 and Tables 2 and 4. Focusing on the first round of all sequences, the average emission is 8.3 in the Immediate treatment, 7.5 in the Halving treatment, and 6.4 in the Persistent treatment. First round emissions exhibit an ascending order from high to no persistence in all sequences (Fig. 2), which is statistically significant at $5 \%$ level in sequence 1 (Table 4, JT test). The bilateral difference between Immediate and Persistent treatments in first round emissions of sequence 1 is also statistically significant at $5 \%$ level (Table 4 , WMW test). 


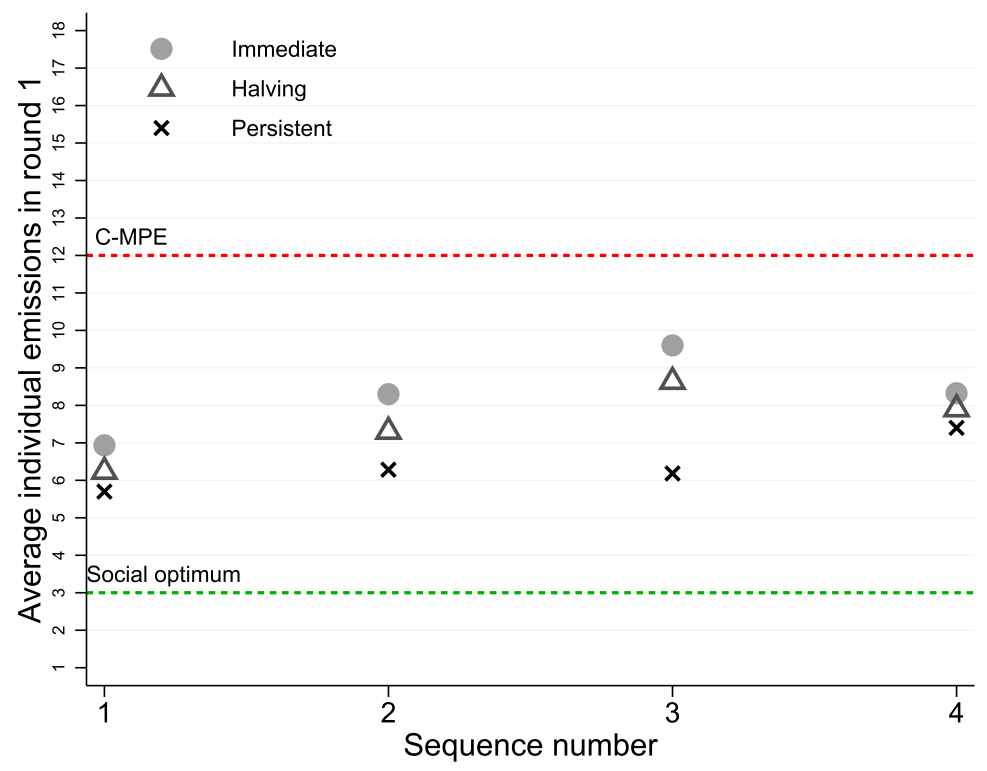

Note: The treatments' ranking remains the same in all sequences. The unit of observation is an individual emission in the first round of a sequence.

Fig. 2. Average emissions in round 1 across sequences.

Table 4

Tests on treatment differences in round 1 emissions.

\begin{tabular}{llll}
\hline & Average emission & $p$-value & Observations \\
\hline Jonckheere-Terpstra test (JT) & & & \\
$\quad$ Immediate > Halving > Persistent & $6.9,6.2,5.7$ & 0.020 & $60,60,60$ \\
Wilcoxon-Mann-Whitney tests (WMW) & & & \\
$\quad$ Immediate vs. Persistent & $6.9,5.7$ & 0.043 & 60,60 \\
$\quad$ Immediate vs. Halving & $6.9,6.2$ & 0.423 & 60,60 \\
$\quad$ Halving vs. Persistent & $6.2,5.7$ & 0.193 & 60,60 \\
\hline
\end{tabular}

Note: First round of sequence 1 only. The unit of observation is a participant. The null hypothesis in JT and WMW tests is that the samples come from the same population. In JT, the alternative hypothesis is that the medians are ordered by persistence as shown in the table.

Tobit regressions on emissions in the first round confirm the finding that Persistent is lower than Immediate when controlling for a host of relevant variables (Table 2). The finding is statistically significant both when considering only sequence 1 (col. 1) and when considering all sequences (col. 2). ${ }^{24}$

As we will see in the next result, while the Persistent treatment starts with emissions lower than the other treatments, it also exhibits a steeper trend.

Result 3 (Trend). Emissions in the Persistent and Halving treatments exhibit a significantly steeper trend over the rounds of a sequence than in the Immediate treatment.

Support for Result 3 is provided by Fig. 3 and Table 3. The trends of average emissions over the rounds within a sequence are shown in Fig. 3. One can see steep linear trends for both the Halving and the Persistent treatments, which are statistically significant at $1 \%$ level according to a Tobit regression on individual choices (Table 3, col. 2 and 4). Instead, no statistically significant linear trend is present in the Immediate treatment (col. 1).

At the sub-sequence level, Fig. 3 suggests that an upward trend in emissions within a sequence is also present in the Immediate treatment approximately until round 10 . That trend then flattens in later rounds. Tobit regressions where we pool data from all treatments confirm the graphical evidence (Table C.5 of the Appendix, col. 3): when considering only the first 10 rounds of all sequences, the estimated coefficient of the trend is positive and statistically significant also in Immediate $(p$-value $<0.001)$.

\footnotetext{
${ }^{24}$ Result 2 - as well as the other results in this section - is robust when controlling for situations where a participant's cumulative earnings were negative, thus in the region of limited liability. The dataset always includes choices under limited liability, which is the situation where the participant's cumulate earnings dropped below $€ 10$ or started monotonically decreasing after reaching a maximum below $€ 10$. In terms of number of choices, 235 in Immediate, 342 in Halving, and 0 in Persistent. None of the results changes when choices under limited liability are omitted.
} 


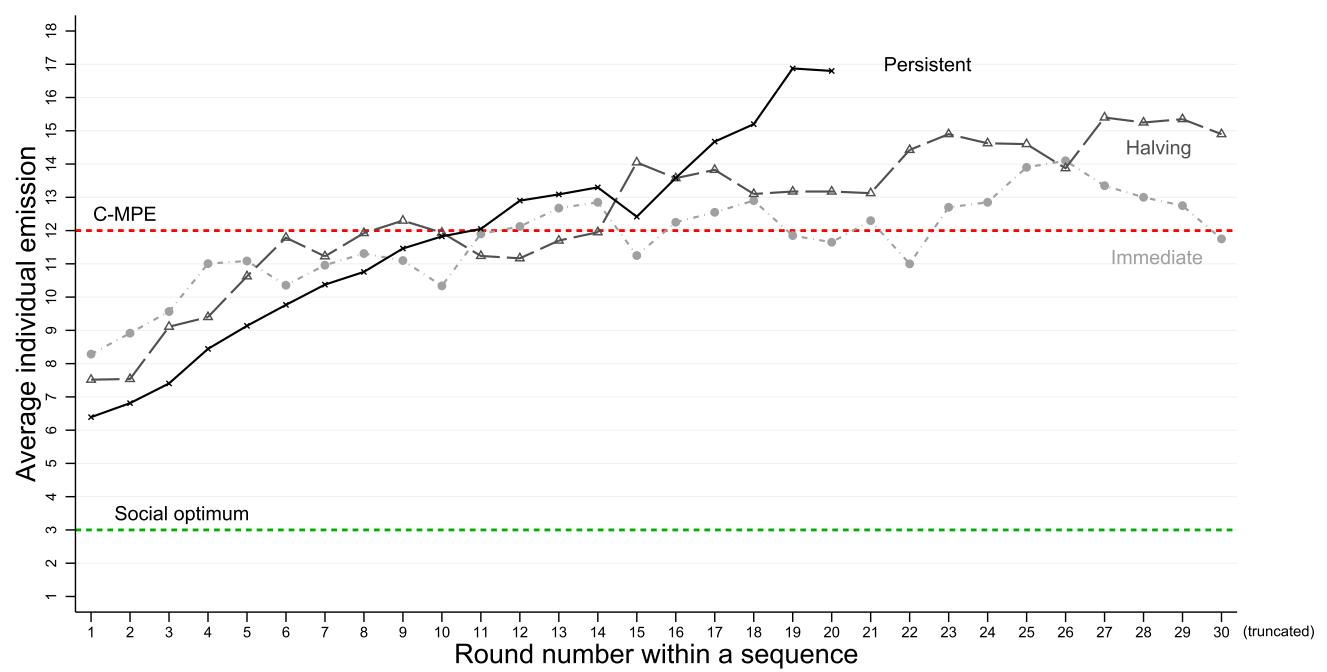

Note: The unit of observation is a group in a round. Every round contains observations from all sessions and all sequences implemented in a session (3 or 4 depending on the session). Due to the random termination of the sequences, the number of observations decreases over rounds: in round $1 N=55$ in Immediate, and $N=60$ in Halving and Persistent, see also footnote 25.

Fig. 3. Aggregate emissions over the rounds.

However, even within the first 10 rounds the trends of Persistent and Halving are significantly steeper than the trend in Immediate ( $p$-value $<0.001$ and $p$-value $=0.037$, respectively). These treatment differences are robust to a number of relevant controls, including the evolution over sequences, the length of past sequences, and level of participants' understanding. ${ }^{25}$

Given the expected duration of a sequence set by design at 12.5 rounds, the combination of Results 2 and 3 explains why we do not find an aggregate treatment effect. Dynamic externalities induce participants to reduce initial emissions, as compared with static externalities, but at the same time they are associated with emissions that increase more over the rounds and thus take-over those in the Immediate treatment. In the Immediate treatment participants also start from a somewhat low emissions level possibly to give cooperation a chance. However, they begin scaling up emissions when observing deviations to higher emissions. It is notable that the upward trend that we identified in Immediate disappears around round 10, when the average emission is close to the C-MPE. At that point participants play the same best-response emission to the Nash equilibrium and emissions stop growing.

To uncover the behavioral channels behind Results 2 and 3, the next three results give an assessment of the strategies adopted by the participants in the different treatments as compared to our theoretical benchmarks. We will first evaluate the share of participants that adopt constant strategies (Proposition 1) against the percentage of those who display non-constant patterns. We will then investigate whether changes in emissions are more in line with a behavior ensuing from the adoption of trigger strategies (Proposition 2) or if they are instead the outcome of stock-dependent strategies (Proposition 3).

Result 4 (C-MPE). The constant Markov perfect equilibrium describes at most $5 \%$ of the individual strategies in any treatment.

The C-MPE equilibrium is a poor predictor of behavior in our experiment. This conclusion is remarkably similar across treatments. When taking to the data the C-MPE equilibrium of an individual emission of 12 in every round (Proposition 1), one can hardly find any support: less than $1 \%$ of participants fit this definition. ${ }^{26} \mathrm{~A}$ more generous definition of C-MPE that includes all individuals emitting 12 plus or minus 2 in every round fits 4\% of participants in Immediate, $2 \%$ in Halving, and 3\% in Persistent. When taking as reference the average emission of a group in a sequence, this classification yields similar results: $4 \%$ in Immediate and Halving, $5 \%$ in Persistent.

How many participants instead managed to sustain the social optimum? Result 5 addresses this question by applying the same technique as employed in Result 4.

\footnotetext{
${ }^{25}$ Due to the indefinite horizon, our dataset is unbalanced. Table C.5 in Appendix also reports a robustness check where we truncate observations at round 20 in order to deal with a more balanced dataset (col. 2). Focusing only on the first 20 rounds does not change the essence of any of the results although a positive but weaker trend is here found in the Immediate treatment too. The difference in trends between Immediate and Persistent remains strong ( $p$-value $<0.001$ ). The difference between Immediate and Halving trends is instead somewhat weaker ( $p$-value $=0.107$ ). Finally, checking for non-linear trends, Persistent and Halving treatments still exhibit significantly steeper trends than Immediate.

${ }^{26}$ The unit of observation is a participant in a sequence: $N=180$ in Immediate, $N=100$ in Halving, $N=240$ in Persistent. Only sequences of three or more rounds are considered.
} 
Table 5

Classification of groups based on emissions in the first and last round.

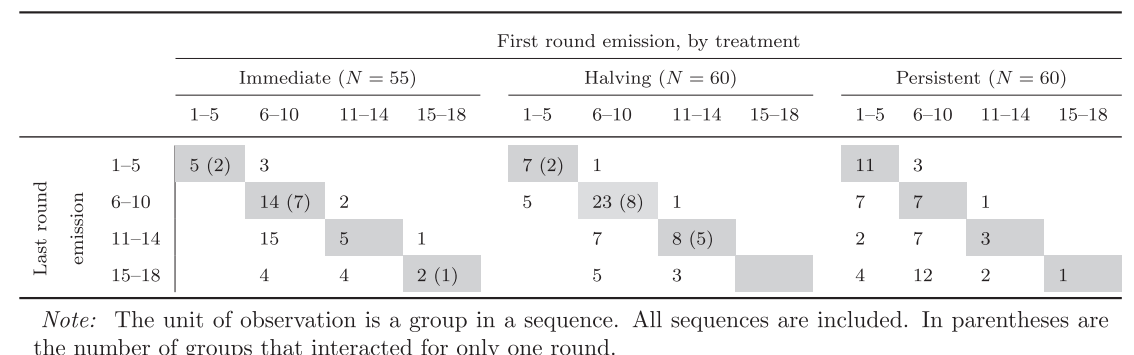
the number of groups that interacted for only one round.

Result 5 (Social optimum). A minority of participants - less than one third - always choose near-socially optimal emission levels. The socially optimal outcome has some empirical attraction, especially in the Persistent treatment. At the group level, nobody in Immediate or Halving was able to achieve a group average emission of 3 in every round of a sequence. In Persistent only $2 \%$ of groups managed to do so. When applying a more generous definition of social optimum, which is a constant emission of 5 plus or minus 2 , one can classify as closer to the social optimum about $13 \%$ of groups in Immediate, $12 \%$ in Halving, and $28 \%$ in Persistent. This is similar to the classification of individuals with this more generous definition: $13 \%$ of participants in Immediate, $8 \%$ in Halving, and $31 \%$ in Persistent. ${ }^{27}$

In Results 4 and 5 we attempted to classify each individual in a sequence considering just one constant emission level. Here we generalize this exercise by classifying an individual as constant if she follows any of the eighteen possible levels of constant emissions. In the experiment, only a minority of individuals actually followed a constant strategy when allowing a bandwidth of $+/-2: 25 \%$ in Immediate, $17 \%$ in Halving, and $47 \%$ in Persistent.

An additional analysis at the group level provides further insights into non-constant behavior. Table 5 partitions the emission space into sixteen cells based on the initial and last emission, where groups exhibiting no trend in emissions are on the main diagonal (shaded area). Among the groups that interacted for at least two rounds, those with roughly constant emissions are 36\% in Immediate (16/45), 51\% in Halving (23/45), and 37\% in Persistent (22/60). Consistently with the previous analyses, many groups do not fit a constant strategy classification. Moreover, Table 5 shows that groups starting with high emissions rarely became cooperative. The ratio of the number of groups with strictly increasing vs. strictly decreasing trend is about $4: 1$ in Immediate, 10:1 in Halving, and 9:1 in Persistent. In line with Result 2, groups in Halving and Persistent are statistically significantly more likely to start with an average emission close to the social optimum (interval 1-5) than in Immediate (Probit regression: Immediate vs. Halving $p$-value $=0.173$, Immediate vs. Persistent $p$-value $=0.013, N=175) .{ }^{28}$ Consistently with Result 3, approximately $50 \%$ of these cooperative groups exhibit higher emissions by the end of the game in both dynamic treatments.

With our theory we can identify two explanations for participants changing and increasing their emissions. They may react to others' deviations, as with trigger strategies (Proposition 2 and Result 6) or they may follow stock-dependent strategies (Proposition 3 and Result 7).

Result 6 (Trigger strategies). Participants using trigger-strategies activated by deviations were estimated at between 21\% and $36 \%$ depending on the treatment.

Participants following a trigger strategy should punish others' defections from the cooperative play by increasing their own emissions (Proposition 2). We follow the algorithm employed in Ghidoni et al. (2017) to identifying emission patterns in line with strategies of a trigger-type, that is, an individual who transitions from a cooperative mode to a punishment mode in the round following a defection event. The unit of observation of this analysis is a participant in a sequence that lasted three or more rounds. The algorithm focuses on all the instances where one observes the maximal positive jump in emissions made by a participant between two subsequent rounds. We interpret these maximal jumps as possible candidates for the switch to a punishment mode. An individual is hence classified as a trigger-type if two conditions are met. First, immediately before the first instance of maximal jump the individual experienced a defection by other group members. We consider as defection any positive increase in others' average emissions between two rounds before and the round preceding that with the maximal jump, i.e. $\bar{e}_{-i}(t-1)-\bar{e}_{-i}(t-2)>0$ where $\bar{e}_{-i}$ is the average emission of the other three group members. Second, in the presence of multiple instances of maximal jump within the same sequence, the algorithm requires that the mean emission of the others in the two rounds before the jumps was strictly increasing on average.

According to the algorithm, participants in a sequence that can be identified as following a trigger strategy are $34 \%(75 / 220)$ in Immediate, 21\% (51/240) in Halving, and 36\% (86/240) in Persistent. These shares are statistically indistinguishable when

\footnotetext{
27 The socially optimal emission of 3 remains at the lower bound of the interval considered. When focusing on longer sequences treatment differences are similar. For example, when considering only sequences that lasted at least 6 rounds (instead of 3), classified participants are $8 \%$ in Immediate, 3\% in Halving, and $14 \%$ in Persistent.

${ }^{28}$ The Probit regression includes data from all sequences and controls for treatment dummies, sequence number, length of current and past sequence. Standard errors are clustered at session-level.
} 
(a) Persistent

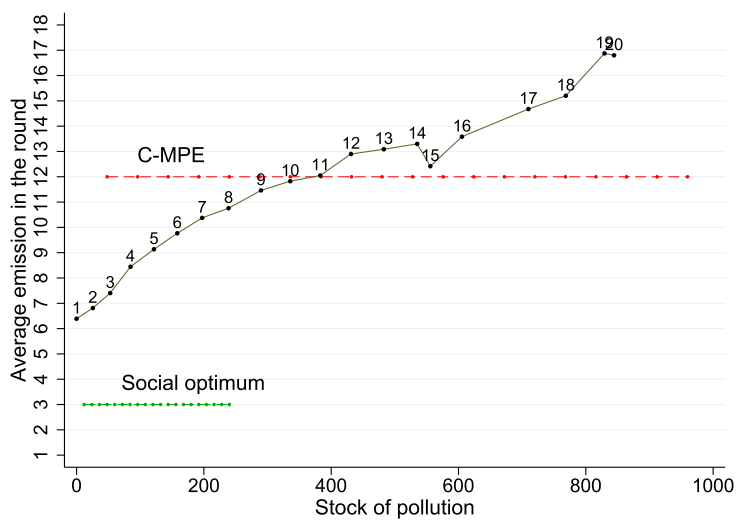

(b) Halving

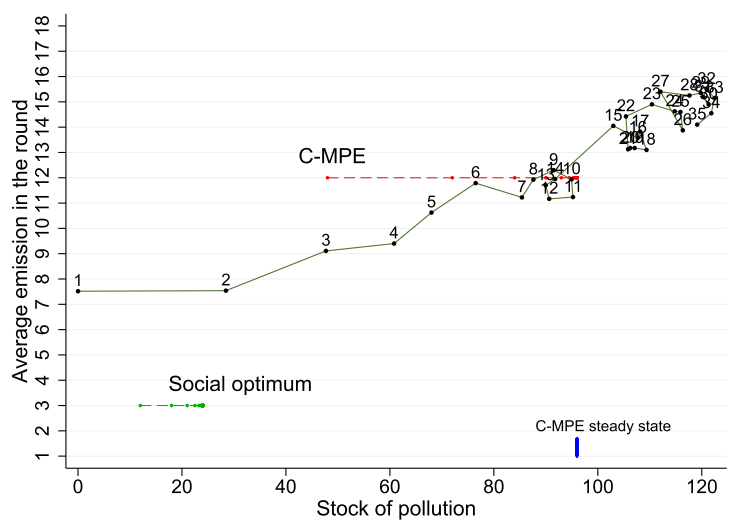

Note: One observation is the average emission of each group in a round of a sequence. All sequences are included. Each dot is the average of all groups in a round over all sequences. The number next to each dot indicates the round number within a sequence. The stock of pollution is measured at the beginning of the round.

Fig. 4. Participants' emissions depend on the stock of pollution.

comparing Immediate vs. Halving and Immediate vs. Persistent. The share of trigger-types in Halving is significantly lower than in Persistent (Wald test in Table C.6 of the Appendix).

While this algorithm clearly relies on some behavioral assumptions, it can capture emission patterns that are consistent with both grim trigger and $T$-rounds punishment strategies. ${ }^{29}$ The outcome presented should not, however, be regarded as an exact estimate but rather an approximate one. The algorithm classifies as trigger-types individuals who reverted to (higher) emissions different from the C-MPE (as it should instead be the case in C-TE strategies). The classification of the algorithm is also not a necessary condition for trigger-types. It may fail to classify as such an individual who follows a trigger strategy if the trigger is never activated. Overall, this procedure may overestimate or underestimate the number of participants using these strategies. Hence, we performed a further analysis focusing on non-constant types, where the algorithm has better chances to identify trigger strategies.

In particular, one can intersect the two classification criteria, trigger-strategy vs. constant strategy with a bandwidth of plus or minus 2. In this new analysis, about half of participants that follow a non-constant strategy can be classified as trigger-types. More precisely, the shares are about 49\% (63/128) in Immediate, 55\% (46/83) in Halving, and 52\% (67/128) in Persistent. Instead, much smaller shares of individuals that follow a constant strategy can be classified as trigger-types: $13 \%$ (12/92) in Immediate, 5\% (5/157) in Halving, and 17\% (19/112) in Persistent.

Alternatively to trigger strategies, participants who exhibit non-constant emissions may have followed stock-dependent strategies (Proposition 3).

Result 7 (Stock-dependent strategies). In the Halving and Persistent treatments, the lagged level of the stock in a sequence is on average positively correlated with the current individual emissions.

Support for Result 7 is provided by Fig. 4 and Table 3. In the Halving and Persistent treatments, the emissions of the average participant positively correlate with the level of the stock of pollution in the group as shown by Tobit regressions in Table 3 (col. 3 and 5). This empirical exercise suffers from the limitation that - due to the experimental design - the correlation between rounds and the stock of pollution is rather strong. Nevertheless, by exploiting the data variability across groups, we can disentangle the correlation between emissions and the stock from that between emissions and a simple time trend. When including both the rounds in a sequence and the stock of pollution as regressors, the coefficient of the time trend ("Round number within a sequence") becomes negative, while the coefficient of the stock is positive and statistically significant, which suggests a preeminence of the stock over the time trend variable in explaining the increasing dynamic of emissions. ${ }^{30}$ This result suggests that on average participants adopted stock-dependent strategies. However, considering the large heterogeneity in individual strategies highlighted by Results 4-6, our analysis cannot rule out that the share of participants using stock-dependent strategies is still a minority.

Fig. 4 illustrates average emissions in a given round as a function of the stock of pollution. The theoretical benchmarks of

\footnotetext{
${ }^{29}$ As discussed in Proposition 2, the social optimum can be also sustained with a limited period of punishment because in our experiment the discount factor parameter $\delta$ is high.

${ }^{30}$ Differences in the magnitude of the stock coefficients are attributable to the rescaling of the damage coefficient $c$ across treatments (Table 1 ).
} 
social optimum and C-MPE are represented by flat lines. Empirically, in the Persistent treatment, the higher the stock, the higher were average emissions (Fig. 4a). As a possible consequence of the ever-increasing stock in Persistent, about one third of groups end up with average emissions above 15 (19 out of 60 groups, in contrast with 9 out of 45 in Immediate and 8 out of 45 in Halving; see Table 5).

In the Halving treatment participants' strategies are generally increasing in the stock of pollution but we frequently observe "cycles" at given levels of stock (Fig. 4b). A cycle takes place when both the stock of pollution and the global emissions of the group simultaneously decrease from one round to the next, but later they start increasing again. In the Halving treatment, 15 out of 20 groups that played more than three rounds experience a cycle. The decreasing phase of a cycle takes place at stock levels between 34 and 142, with an average of 101, which is close to the predicted steady-state stock of 96 under C-MPE. ${ }^{31}$ This pattern is consistent with the strategies illustrated in Proposition 3 and with the "greenhouse trap" suggested in Dutta and Radner (2009). When following stock-dependent strategies, the convergence to a stock may take place from below (with increasing emissions) or from above (with decreasing emissions). ${ }^{32}$

As shown in Fig. 4, in the dynamic treatments, the pollution stock often exceeds C-MPE levels, which is not predicted by equilibrium behavior of the theoretical analysis. This pattern is confirmed by more disaggregated analyses. The stock was above the C-MPE level for at least three rounds, not necessarily consecutive, in $60 \%$ of the groups of the Halving treatment and in $13 \%$ of the groups of the Persistent treatment. ${ }^{33} \mathrm{~A}$ possible behavioral interpretation for the higher frequency of stock overshooting in Halving vs. Persistent may be that participants in Halving have the impression of being able to control the stock of pollution and reduce it if necessary, as shown by the "cycles". In Persistent, instead, participants may be more cautious because of stronger persistence. $^{34}$

\section{Discussion and conclusions}

To foster international efforts to combat climate change, we need a thorough grasp of those factors that hinder or favor cooperation. Here we employ the experimental method to gain an understanding of behavioral drivers that are considered crucial in overcoming this special type of social dilemma. In particular, the focus is on a central issue of climate change: the long-term persistence of key greenhouse gases in the atmosphere, which generates irreversibility. We developed an experimental platform carefully calibrated to identify the causal effect of different degrees of persistence of pollution on the ability to cooperate in mitigating emissions. We compare settings that cover the full range of possibilities: a static (although repeated) treatment with no persistence, a dynamic treatment where emissions cumulate and last forever, and an intermediate treatment with a decay in pollution at a rate of $50 \%$ every round.

We report three main findings. First, the persistence of pollution leads to a high initial cooperation level (Result 2). This contrasts with what one may conjecture: a scenario where today's actions have only immediate consequences could be expected to elicit more cooperation than a complex scenario with diluted and persistent consequences over time.

Second, although the previous result seems reassuring, we also report that, when pollution accumulates because of persistence, cooperation declines (Result 3). This may be explained with the adoption of trigger strategies reacting to (deviating) current emissions or strategies that are increasing in the stock of pollution. These strategies are indeed equilibria of the game with dynamic externalities. Our evidence suggests that the increasing trend in emissions emerging in the Halving and Persistent treatments is linked to the stock of pollution rather than to time or experience (Result 7). With Markov strategies, the level of the stock of pollution can become a coordination device that is not available when persistence is nil (Proposition 3). However, this type of coordination is a difficult endeavor. With persistence, lower initial emissions may be a clever way to learn others' intentions toward cooperation in the presence of irreversibility. However, cooperation is not perfectly controllable by a single decision-maker because the stock of pollution reflects the emissions of all decision-makers. Hence, it can be easily depleted and, when cooperation breaks down, the stock keeps growing.

Third, behavioral differences in emissions between rich and poor types as modeled in the experiment reported here are of second-order importance (Result 1). The extent to which the rich participants emit less than poor ones is rather small, and it is especially evident with dynamic externalities. This empirical result is consistent with the theoretical predictions of our environment and suggests that rich participants are not willing to contribute much more than poor participants to the mitigation efforts, even if mitigation is more demanding for the poor in terms of welfare. As a consequence, there is a wide earnings gap between poor and rich types.

Any economic experiment on climate change is necessarily a study in a highly simplified setting with some restrictive assumptions. This is also true in our case. Take for example the damage function: in the laboratory, impacts are immediate and deterministic instead of delayed and stochastic (Ghidoni et al., 2017). Uncertainty or limited perception of the actual environment may impair decision-makers' ability to cooperate. Also the initial level of pollution stock, zero in all our treatments,

\footnotetext{
${ }^{31}$ A group-by-group graphical analysis is in Figs. C.1 and C.2 of the Appendix. In Halving, 40\% of the groups display more than one decreasing phase over the sequence. In Persistent, instead, it can be observed that the majority of the groups display a positive relationship between stock and emissions.

32 This pattern is the one illustrated in Fig. 4b and Fig. C.2 in Appendix, precisely "around" the C-MPE steady-state stock.

33 These percentages refer to groups that interacted for at least three rounds: $N=25$ in Halving and $N=60$ in Persistent.

34 Stock and emissions above C-MPE levels may be the outcome of temporary punishment phases of sophisticated non-Markov behavior off equilibrium. This is a theoretical possibility which, however, requires high levels of sophistication and coordination among individuals and strategies that depend not only on the stock of pollution but also on the precise date of the period.
} 
may play a role. Future work can remedy these and other limitations of our approach. Nevertheless, we believe that experiments are additional means to further our understanding of how to foster international cooperation in tackling climate change.

This study makes a novel contribution to the behavioral components of cooperation to solve the climate change problem by addressing the issue of pollution persistence. One cannot take findings from laboratory experiments and use them directly to give policy advice. Caution should be exercised in this transfer of knowledge because the external validity of economic experiments on climate change is not automatic. Yet our results have some relevance for the research agenda on climate change and can complement available field evidence. Scholars have claimed that persistence severely affects the ability of nations to cooperate, but the empirical support is lacking. With a simple model of climate change, our study suggests that policy-makers should not delay mitigation actions until the situation deteriorates, because the experimental evidence suggests that cooperation becomes harder than it was early on. In the experiment, the climate model involves bottom-up mitigation efforts but does not include a system of pledges similar to the one that led to the Paris agreement. Voluntary pledges allow for common but differentiated responsibilities in mitigation of poor and rich regions. In our climate game, satisfying the right for development of poor regions risks derailing the overall cooperative equilibrium. Rich regions should be willing to restrict emissions voluntarily in order to ensure the right to development of poor regions, but this tendency is rather weak in the experiment. One solution could be explicitly agreeing on distinct targets of emissions by income level, which would at the same time sustain a strong aggregate mitigation and the right to development. Carbon is forever, but the good news is that, at least in the short-term, this will not initially condemn us to suffer from lack of cooperation any more than in the usual static social dilemmas. Nevertheless, when taking a long-run perspective, policy interventions are urgent and must start as soon as possible.

\section{Appendix A. Supplementary material}

Supplementary material to this article can be found online at https://doi.org/10.1016/j.jeem.2018.09.002.

\section{References}

Andreoni, J., 1995. Warm-glow versus cold-prickle: the effects of positive and negative framing on cooperation in experiments. Q. J. Econ. 110 (1), 1-21.

Barrett, S., Dannenberg, A., 2012. Climate negotiations under scientific uncertainty. PNAS 109 (43), 17372-17376.

Barrett, S., Dannenberg, A., 2014. Sensitivity of collective action to uncertainty about climate tipping points. Nat. Clim. Change 4 (1), 36-39.

Battaglini, M., Nunnari, S., Palfrey, T.R., 2016. The dynamic free rider problem: a laboratory study. Am. Econ. J. Microecon. 8 (4), $268-308$.

Bosetti, V., Carraro, C., Tavoni, M., 2012. Timing of mitigation and technology availability in achieving a low-carbon world. Environ. Resour. Econ. 51 (3), 353-369.

Bosetti, V., Heugues, M., Tavoni, A., 2017. Luring others into climate action: coalition formation games with threshold and spillover effects. Oxf. Econ. Pap. 69 (2), 410-431.

Burke, M., Hsiang, S., Miguel, E., 2015. Global non-linear effect of temperature on economic production. Nature 527 (7577), 235-239.

Camera, G., Casari, M., 2009. Cooperation among strangers under the shadow of the future. Am. Econ. Rev. 99 (3), $979-1005$.

Dal Bó, P., Fréchette, G.R., 2018. On the determinants of cooperation in infinitely repeated games: a survey. J. Econ. Lit. 56(1), 60-114.

Dannenberg, A., Löschel, A., Paolacci, G., Reif, C., Tavoni, A., 2015. On the provision of public goods with probabilistic and ambiguous thresholds. Environ. Resour. Econ. 61 (3), 365-383.

Dutta, P.K., Radner, R., 2004. Self-enforcing climate-change treaties. PNAS 101 (14), 5174-5179.

Dutta, P.K., Radner, R., 2009. A strategic analysis of global warming: theory and some numbers. J. Econ. Behav. Organ. 71 (2), $187-209$.

Falk, A., Heckman, J.J., 2009. Lab experiments are a major source of knowledge in the social sciences. Science 326 (5952), $535-538$.

Fiala, L., Suetens, S., 2017. Transparency and cooperation in repeated dilemma games: a meta study. Exp. Econ. 20 (4), $755-771$.

Fischbacher, U., 2007. z-Tree: Zurich toolbox for ready-made economic experiments. Exp. Econ. 10 (2), $171-178$.

Gerlagh, R., van der Heijden, E., 2015. Going green: framing effects in a dynamic coordination game. CentER Discussion Paper $2015-054$.

Ghidoni, R., Calzolari, G., Casari, M., 2017. Climate change: behavioral responses from extreme events and delayed damages. Energy Econ. 68 (1), 103-115.

Greiner, B., 2015. Subject pool recruitment procedures: organizing experiments with ORSEE. J. Econ. Sci. Assoc. 1 (1), $114-125$.

Hauser, O.P., Rand, D.G., Peysakhovich, A., Nowak, M.A., 2014. Cooperating with the future. Nature 511 (7508), $220-223$.

Herr, A., Gardner, R., Walker, J.M., 1997. An experimental study of time-independent and time-dependent externalities in the commons. Game. Econ. Behav. 19 (1), 77-96.

Inman, M., 2008. Carbon is forever. Nat. Rep. Climate Change 156-158.

IPCC, 2007. Climate Change 2007: the Physical Science Basis. Contribution of WGI to 4th Assessment Report of IPCC. Cambridge University Press.

IPCC, 2014. Climate Change 2014: Mitigation of Climate Change. Contribution of WGIII to 5th Assessment Report of IPCC. Cambridge University Press.

JRC, PBL, 2016. The Emissions Database for Global Atmospheric Research (EDGAR). Available at: http://edgar.jrc.ec.europa.eu/.

Khadjavi, M., Lange, A., 2015. Doing good or doing harm: experimental evidence on giving and taking in public good games. Exp. Econ. 18 (3), $432-441$.

Köke, S., Lange, A., 2017. Negotiating environmental agreements under ratification constraints. J. Environ. Econ. Manag. 83, $90-106$.

Laury, S., Holt, C., 2008. Voluntary provision of public goods: experimental results with interior nash equilibria. In: Plott, C., Smith, V. (Eds.), Handbook of Experimental Economics Results, vol. 1, pp. 792-801 North-Holland.

Milinski, M., Sommerfeld, R.D., Krambeck, H.-J., Reed, F.A., Marotzke, J., 2008. The collective-risk social dilemma and the prevention of simulated dangerous climate change. PNAS 105 (7), 2291-2294.

Nordhaus, W.D., 2013. The Climate Casino: Risk, Uncertainty, and Economics for a Warming World. Yale University Press.

Pevnitskaya, S., Ryvkin, D., 2013. Environmental context and termination uncertainty in games with a dynamic public bad. Environ. Dev. Econ. 18 (01), 27-49.

Sherstyuk, K., Tarui, N., Ravago, M.-L.V., Saijo, T., 2016. Intergenerational games with dynamic externalities and climate change experiments. J. Assoc. Environ. Resour. Econ. 3 (2), 247-281.

Stern, N.H., Treasury, H.M., et al., 2006. Stern Review: the Economics of Climate Change. Cambridge University Press.

Tavoni, A., Dannenberg, A., Kallis, G., Löschel, A., 2011. Inequality, communication, and the avoidance of disastrous climate change in a public goods game. PNAS

108 (29), 11825-11829.

Wagner, G., Weitzman, M.L., 2015. Climate Shock: the Economic Consequences of a Hotter Planet. Princeton University Press. 